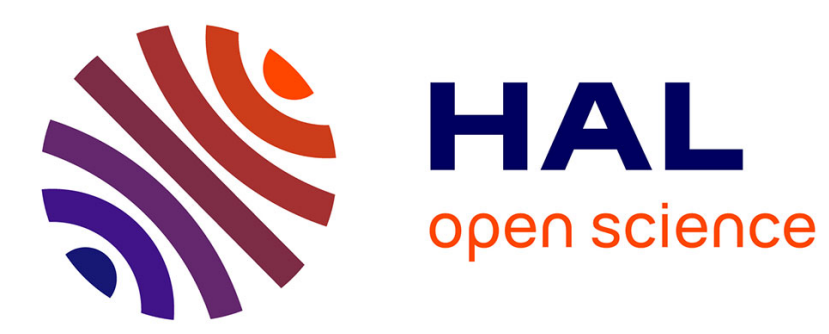

\title{
AlN/Sapphire: a promising structure for high temperature and high frequency SAW devices
}

Eloi Blampain, Omar Elmazria, Thierry Aubert, Badreddine Assouar, Ouarda Legrani

\section{- To cite this version:}

Eloi Blampain, Omar Elmazria, Thierry Aubert, Badreddine Assouar, Ouarda Legrani. AlN/Sapphire: a promising structure for high temperature and high frequency SAW devices. IEEE Sensors Journal, 2013, 13 (12), pp.4607-4612. 10.1109/JSEN.2013.2271863 . hal-00923015

\section{HAL Id: hal-00923015 https://hal.science/hal-00923015}

Submitted on 17 Apr 2020

HAL is a multi-disciplinary open access archive for the deposit and dissemination of scientific research documents, whether they are published or not. The documents may come from teaching and research institutions in France or abroad, or from public or private research centers.
L'archive ouverte pluridisciplinaire HAL, est destinée au dépôt et à la diffusion de documents scientifiques de niveau recherche, publiés ou non, émanant des établissements d'enseignement et de recherche français ou étrangers, des laboratoires publics ou privés. 


\title{
AlN/Sapphire: a promising structure for high temperature and high frequency SAW devices
}

\author{
Eloi Blampain ${ }^{1,2,3}$, Omar Elmazria ${ }^{1,2}$ IEEE member, Thierry Aubert ${ }^{1,2 *}$, Badreddine Assouar ${ }^{1,2}$ \\ and Ouarda Legrani ${ }^{1,2}$, \\ ${ }^{1}$ Institut Jean Lamour (IJL), UMR7198 Université de Lorraine, 54506 Vandoeuvre lès Nancy, France \\ ${ }^{2}$ Institut Jean Lamour (IJL), UMR7198 CNRS, 54506 Vandoeuvre lès Nancy, France \\ ${ }^{3}$ Unité de Recherche en Physique (URPHY), Masuku University, Franceville, Gabon
}

\begin{abstract}
In this work, the performance of AlN/Sapphire structure in high frequencies is investigated. Several SAW devices were fabricated with various designs (free-space delay, wavelength, metallization ratio, ...) to study simultaneously different parameters (acoustic velocity, electromechanical coupling $\left(\mathrm{K}^{2}\right)$, acoustic propagation loss $(\alpha)$, TCF) versus frequency and temperature. Experimental results showed that as expected, $\alpha$ increases with temperature while $K^{2}$ is enhanced at high temperatures. Due to the antagonistic evolution of these two parameters, insertion loss decreases or increases as function of the free-space delay. We also demonstrated that this structure allows fabrication of devices operating up to $1.5 \mathrm{GHz}$ and that the frequency varies linearly with temperature.
\end{abstract}

Key word-SAW sensor, High temperature, AlN, Sapphire

\section{INTRODUCTION}

SAW devices offer very promising solutions in a wide range of sensing applications. Their use as passive and wireless sensors allows them to operate in extreme conditions such as high temperatures or radioactive environments (up to $1000^{\circ} \mathrm{C}$ ) in which no other wireless sensor can operate [1]. Nowadays, It is well established that Langasite (LGS) is the current reference as substrate for high temperature use [2]. However, LGS presents a serious limitation at high frequency (up to $1 \mathrm{GHz}$ ) related to a strong increase of acoustic propagation losses $(\alpha)$ with temperature [1]. In previous works [3], we reported on the reliability of AlN/Sapphire structure in high temperature applications (up to $900^{\circ} \mathrm{C}$ ). The same structure was investigated using Platinum interdigital transducer (IDT) and frequency response of SAW delay line

Manuscript received December 30, 2012. This work was supported in part by the by the French Ministry of Research and by the "Région Lorraine" via CPER project. The authors also benefited from technical help of Laurent BOUVOT.

*T. Aubert is now with Université de Savoie, Laboratoire SYMME, Annecyle-Vieux, France performed in-situ until $600^{\circ} \mathrm{C}$ have shown that the insertion loss increases by $0.01 \mathrm{~dB} /{ }^{\circ} \mathrm{C}$ [4]. These losses are due to the contribution of several factors, although the reason for increased loss with temperature has not been determined. In this work, we will study separately the evolution with temperature of the electromechanical coupling factor $\left(\mathrm{K}^{2}\right)$ and acoustic propagation loss $(\alpha)$. The aim is to understand the main origin of the insertion losses.

The performance of this structure will be also investigated in high frequency regime but only up to $300^{\circ} \mathrm{C}$ due to IDT nature. Indeed, the IDT was fabricated with aluminum for this study to avoid unexpected additional loss induced by heavy metal as Platinum or Iridium.

\section{EXPERIMENTAL}

Highly oriented c-axis AIN (002) thin film, $1.3 \mu \mathrm{m}$ thick, was grown by reactive magnetron sputtering onto 3" (0001) sapphire wafers [5]. X-ray diffraction (XRD) measurements as well as transmission electron microscopy revealed that the (002) AlN films are stress-free and highly-textured out of the plane, with a full width at half-maximum (FWHM) of the (002) rocking-curve (RC) as low as $0.26^{\circ}$. The value of the grain size and the surface roughness of the film estimated by atomic force microscopy (AFM) are respectively equal to 40 $\mathrm{nm}$ and $8 \AA$ [5]. $150 \mathrm{~nm}$ thick aluminum IDT, were patterned by conventional contact ultraviolet (UV) photolithography. The IDT are single type with uniform finger spacing and various spatial periods $(\mathrm{P}=16,24,36$ and $48 \mu \mathrm{m})$. The number finger pairs is 50 and the IDT aperture equal to $1 \mathrm{~mm}$. For each spatial period, four different free-space delays (gaps) between input IDT were designed as shown in fig. 1, to evaluate the propagation losses versus frequency and temperature $\quad(($ gap $1=10 x P, \quad$ gap $2=30 \times P, \quad$ gap $3=50 \times P$, 1gap4=200xP).

The metallization ratio $(\eta)$ of IDT was set to $33 \%$ in order to generate higher harmonics up to 13 , thus allows investigation of several operating frequencies for each device 
[6]. Thus, larger values of normalized thickness $\left(\mathrm{kh}_{\mathrm{AIN}}\right.$, where $\mathrm{k}=2 \pi / \lambda$ is the wave vector modulus) could be obtained without using large AlN film thickness or high resolution lithography technique leading to a SAW device with high electromechanical coupling. Indeed, theoretical calculations show that $\mathrm{K}^{2}$ increases when the normalized thickness of AlN film increases and reaches a pseudo-plateau when $\mathrm{kh}_{\mathrm{AIN}}=2$ [7].

Taking into account the spatial period of IDT, the order of considered harmonic, and the AlN film thickness, the $\mathrm{kh}_{\mathrm{AIN}}$ value of our samples varies from 2.2 to 6.6 , enabling to perform SAW devices operating up to $1.5 \mathrm{GHz}$. Note that when using a heavy material as platinum to realize IDT, the harmonics are not generated. Its why in this study we decided to use aluminium and limit our investigation to $300^{\circ} \mathrm{C}$.
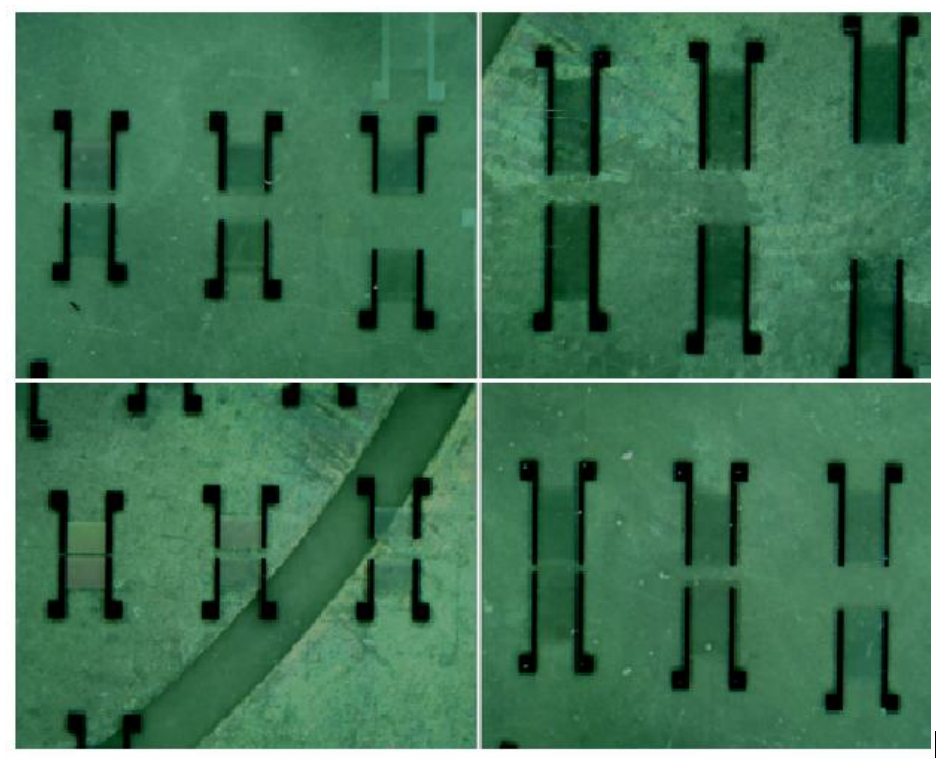

Fig. 1. Photograph of various SAW delay line with different wavelenghts and different free-space delays.

A synchronous SAW resonator operating at $868 \mathrm{MHz}$ was also realized to measure the $\mathrm{K}^{2}$ versus temperature. The wavelength was fixed to $6.5 \mu \mathrm{m}$.

Frequency responses of SAW devices in transmission $\left(\mathrm{S}_{21}\right)$ or in reflection $\left(\mathrm{S}_{11}\right)$ were measured using Network Analyzer (Agilent PNA 5230A, Santa Clara, CA) and RF prober station (Signatone S-1160, Gilroy, CA ) equipped with Signatone Thermal probing system S-1060 Series so that they can withstand temperatures up to $600^{\circ} \mathrm{C}$. However, we restrict our characterization to $300^{\circ} \mathrm{C}$ due to the use of aluminum IDT but also due to the limitation imposed by the use of RF probes (Z Probe SussMicrotech).

\section{RESULTS AND DISCUSSION}

The wide range frequency response, up to $1.6 \mathrm{GHz}$, measured at 25 and $300^{\circ} \mathrm{C}$ on the device corresponding to $\lambda=$ $48 \mu \mathrm{m}$ and gap $=120 \lambda$, is showed on Figure 2. We can observe several peaks related to the mode 0 of the Rayleigh wave and their corresponding harmonics, up to 13 . One can observe that the $7^{\text {th }}$ harmonic $(815 \mathrm{MHz})$ shows lowest insertion losses and highest sidelobe suppression compared to other peaks including the fundamental one. This can be partially explained by the increase of the electromechanical coupling coefficient with normalized thickness of AlN film. Indeed the peak intensities are governed by:

- The electromechanical coupling coefficient value which is dispersive for the layered structures [7].

- The order of harmonic and its relative intensity which is dependent on metallization ratio of IDT $[6,8]$.

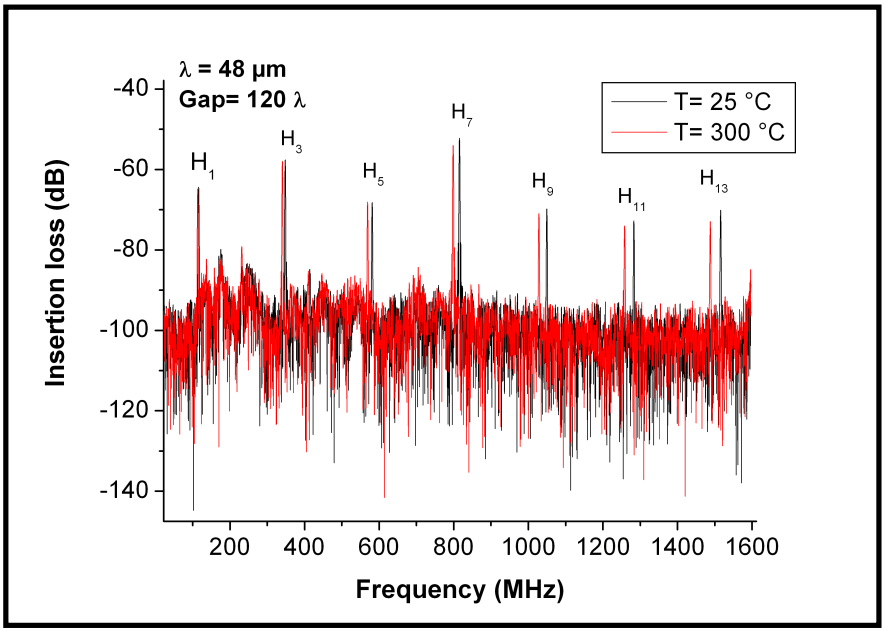

Fig. 2. Wide band frequency response of SAW delay line performed with $\mathrm{hAlN}=1.3 \mu \mathrm{m}$ and $\lambda=48 \mu \mathrm{m}$. Measurement was done at 25 and $300^{\circ} \mathrm{C}$.

Table 1: Synthesis of insertion losses and center frquencies ectracted from figure 2 and calculated $\mathrm{K}^{2}$, fo and relative amplitude for the fundamental peak and the five first harmonics. various harmonics.

\begin{tabular}{|c|c|c|c|c|c|c|}
\hline Peak & $\mathrm{H}_{1}$ & $\mathrm{H}_{3}$ & $\mathrm{H}_{5}$ & $\mathrm{H}_{7}$ & $\mathrm{H}_{9}$ & $\mathrm{H}_{11}$ \\
\hline \multicolumn{1}{|c|}{$\mathrm{kh}_{\text {AIN }}$} & 0.17 & 0.51 & 0.85 & 1.19 & 1.53 & 1.87 \\
\hline $\begin{array}{c}\mathrm{K}^{2}(\%) \\
\text { Calculated }\end{array}$ & 0.015 & 0.125 & 0.18 & 0.24 & 0.27 & 0.27 \\
\hline $\begin{array}{l}\text { Relative } \\
\text { amplitude }\end{array}$ & 1.25 & 0.6 & 0.3 & 0.6 & 0.25 & 0.4 \\
\hline $\begin{array}{l}\text { Measured } \\
\text { IL (dB) }\end{array}$ & -64.3 & -57.6 & -68.2 & -52.2 & -69.8 & -72.7 \\
\hline $\begin{array}{l}\text { foc(MHz) } \\
\text { Calculated }\end{array}$ & 115,6 & 346,4 & 579 & 813,7 & 1049 & 1285 \\
\hline $\begin{array}{l}\text { fo (MHz) } \\
\text { Measured }\end{array}$ & 115.9 & 348.1 & 581.3 & 815.3 & 1049 & 1283 \\
\hline
\end{tabular}

In table 1 were summarized for each peak observed in figure 2, - the related normalized thickness of AlN film $\left(\mathrm{kh}_{\mathrm{AIN}}=2 \pi \mathrm{h} / \lambda\right)$, - calculated values of $K^{2}$ and central frequency $f_{O}=V \phi / \lambda$. 
- measured insertion loss and central frequency

- estimated relative amplitude depending on harmonic order and considered metallization ratio (33\%)

Calculated $\mathrm{K}^{2}$ and fo were extracted from dispersion curve of $\mathrm{K}^{2}$ and phase velocity $(\mathrm{V} \phi)$ published by $\mathrm{C}$. Caliendo [7],

By combining the values of $\mathrm{K}^{2}$ and the relative amplitude listed in Table 1, one can easily understand why the seventh harmonic (H7) exhibits the lowest insertion loss. The fundamental frequency and $\mathrm{H} 3$ are mainly penalized by their very weak coupling while $\mathrm{H} 5$ is penalized by its low relative amplitude.

In order to cancel the relative amplitude contribution, figure 3 shows the frequency responses corresponding to the fundamental frequency of two devices having two different wavelengths $(\lambda=\mathrm{P}=14 \mu \mathrm{m}$ and $\lambda=\mathrm{P}=24 \mu \mathrm{m})$ and the same free space delay $(50 \mathrm{xP})$. Although the propagation loss are expected to be higher at high frequency, the device with $\mathrm{P}=14$ $\mu \mathrm{m}$ exhibits low insertion loss thank to it's higher $\mathrm{K} 2$ value. $0.2 \%$ against $0.1 \%$ for the device with $\mathrm{P}=24 \mu \mathrm{m}$.

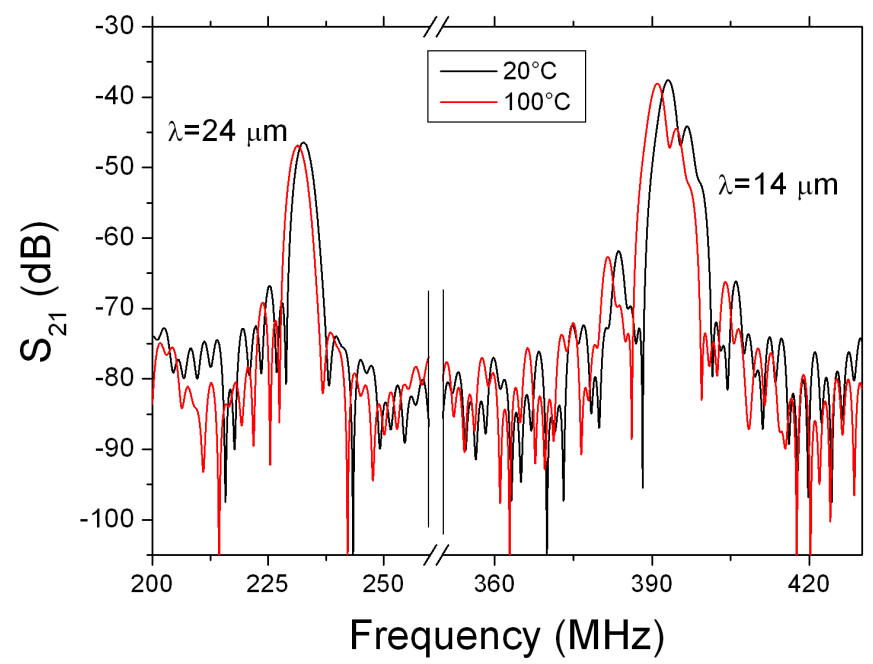

Fig. 3. Frequency response measured for two SAW delay lines $(\lambda=\mathrm{P}=14$ $\mu \mathrm{m}$ and $\lambda=\mathrm{P}=24 \mu \mathrm{m})$. The free space delay is equal to $50 \mathrm{xP}$ fo both devices.

Now, if we compare the frequency response obtained at RT $\left(25^{\circ} \mathrm{C}\right)$ and at $300^{\circ} \mathrm{C}$, we can observe as it is shown in figure 4 , that the insertion losses increase with temperature. However, the origin of the losses increase is not identified and could be due to the increase of the propagation loss $(\alpha)$ with temperature or to the decrease of $\mathrm{K}^{2}$ with temperature. To understand the origin of the insertion loss and to identify the contribution of each element $\left(\alpha\right.$ and $\mathrm{K}^{2}$ ) and their evolution with temperature, we separately measured the variation of $\mathrm{K}^{2}$ versus temperature using a SAW resonator and the insertion loss for various free-space delays using SAW delay lines.

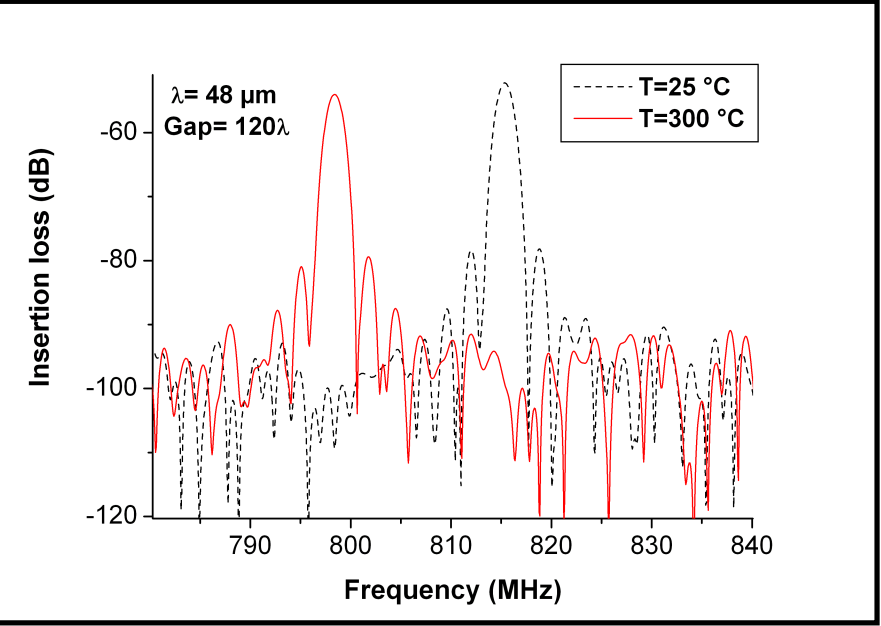

Fig. 4. Frequency response (7th harmonic) of SAW delay line made with $\mathrm{h}_{\mathrm{AIN}}=1.3 \mu \mathrm{m}$ and $\lambda=48 \mu \mathrm{m}$. Measurement was done at 25 and $300^{\circ} \mathrm{C}$.

\section{A. Electromechanical coupling coefficient $K^{2}$}

The experimental $\mathrm{K}^{2}$ was determined using measured data for the $\mathrm{S}_{11}$ parameter (reflection) and the following equation derived from Smith's equivalent model $[9,10]$ :

$$
\alpha=\frac{I L_{2}-I L_{1}}{g a p_{2}-g a p}(d B / \lambda)
$$

where $\mathrm{G}\left(\mathrm{f}_{0}\right)$ and $\mathrm{B}\left(\mathrm{f}_{0}\right)$ are, respectively, the radiation conductance and susceptance measured by network analyzer Smith chart at center frequency $\mathrm{f} 0$, and $\mathrm{N}$ the number of finger pairs of the IDT.

Figures 5, shows that the $\mathrm{K}^{2}$ coefficient increases with temperature. An enhancement of $30 \%$ is recorded when temperature increase from 25 to $300^{\circ} \mathrm{C}$. This demonstrate that the piezoelectrical properties of AlN/Sapphire structure are enhanced with temperature at least up $300^{\circ} \mathrm{C}$. Note that when the device is cooled down, the $\mathrm{K}^{2}$ return to its original value.

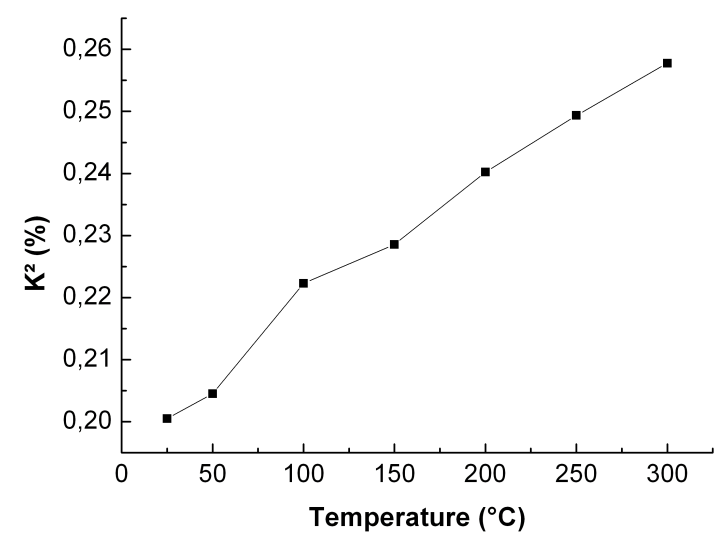

Fig. 5. Evolution of electromechanical coupling coefficient $\left(\mathrm{K}^{2}\right)$ with temperature. 


\section{B. Propagation Loss Measurements}

Propagation losses were determined by measuring the insertion losses of SAW devices with identical geometry, except for the free-space delay. Fig. 6 shows typical frequency responses obtained for SAW \#21 $(\lambda=48 \mu \mathrm{m}$, gap $1=50 \mathrm{P}$, IL $=-64.3 \mathrm{~dB})$ and SAW \#24 $(\lambda=48 \mu \mathrm{m}$, gap $2=120 \mathrm{P}, \mathrm{IL}=$ $-65.1 \mathrm{~dB})$. The propagation loss $(\alpha)$ can be expressed by:

$$
\alpha=\frac{I L_{2}-I L_{1}}{g a p_{2}-g a p}(d B / \lambda)
$$

The measured propagation losses are due to the losses in the AlN layer and in the Sapphire substrate, and the diffraction losses that depend on ITDs geometry and the power flow angle (PFA) of the substrate. In our case, the contribution of diffraction could not be evaluated experimentally, but taking into account the aperture value and the maximum free space delay considered for our devices, we can assume that it is very low compared to other considered losses and it may be ignored inside the band pass. The diffraction affect mainly the suppression loss [11]. Moreover AlN film could be considered as isotropic and the direction of the wave propagation considered on sapphire shows a zero PFA.

The variation of insertion losses with temperature were measured for different free-space delays. Fig. 7 shows the relative variation of these losses obtained for the fundamental peak of devices $\# 2(\mathrm{P}=24 \mu \mathrm{m}$, gap $=10,30,50$ and $120 \mathrm{P})$. If as expected the insertion loss increase with temperature for the device made with the larger free-space delay (gap=120 P), a significant improvement (insertion losses diminution) can be seen for the shortest delay line between room temperature and $300^{\circ} \mathrm{C}$, one can observe a relative stability for intermediate ones.

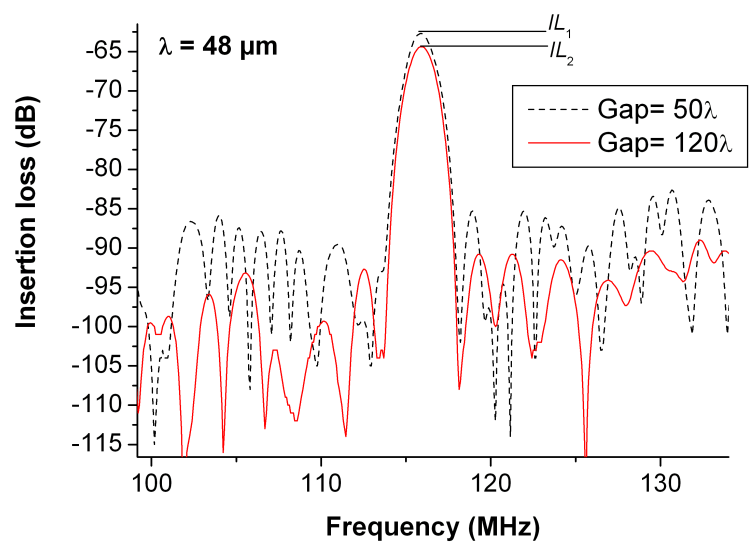

Fig. 6. Insertion loss vs. frequency obtained for SAW_\#21 (P = 48 $\mu \mathrm{m}$, gap1 $=50 \mathrm{P})$ and SAW_\#24 $(\mathrm{P}=48 \mu \mathrm{m}$, gap2 $=120 \mathrm{P})$
Taking into account the improvement of the $\mathrm{K}^{2}$ with temperature (Fig. 4), we can conclude that the propagation losses increase when the temperature is rising and that this phenomenon can counteract the expansion of $\mathrm{K}^{2}$ if the delay line is long enough. Thus and according to the intended application, it is possible by modulating the free-space delay length, to make SAW sensors meet several specifications: constant insertion loss with temperature (middle gap), high sensitivity (large gap) or even an improving the quality of the signal with temperature (small gap).

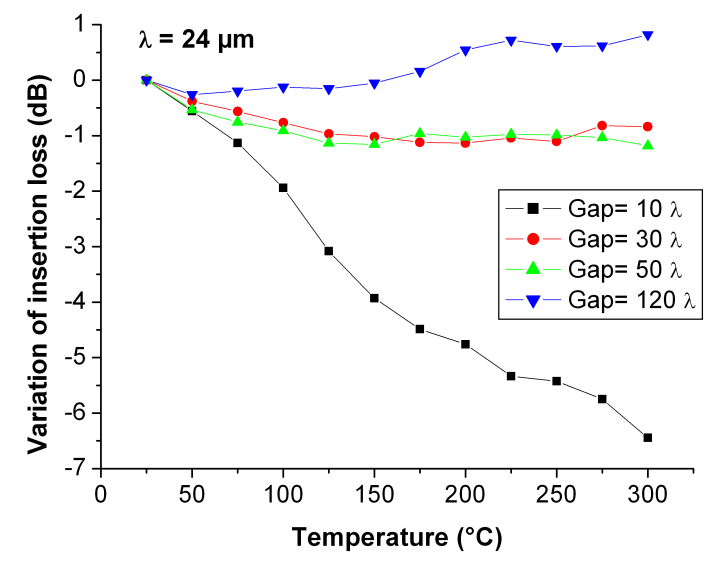

Fig. 7. Relative variation of insertion loss versus temperature measured on devices with various free-space delays.

\section{Temperature coefficient of frequency (TCF)}

To evaluate the potential of the structure as a temperature sensor, the frequency-versus-temperature behavior of IDT/AIN/Sapphire SAW delay lines were investigated. Figure 8 , shows the frequency-temperature characteristics obtained from devices \#2. The investigated structure is characterized by a large and quasi-constant sensitivity to temperature, with first-order temperature coefficient of frequency (TCF) values equal to $-67.6 \mathrm{ppm} /{ }^{\circ} \mathrm{C}$ making it well suited for temperature sensor applications. As expected, this characteristic does not depend on the considered free-space delay.

On the other hand, we analyzed evolution of relative frequency variation versus temperature as shown in Figure 9, for harmonics $\mathrm{H}_{1}, \mathrm{H}_{5}, \mathrm{H}_{9}$ and $\mathrm{H}_{13}$. For each wave length corresponding to different $\mathrm{Kh}_{\text {AlN }}$, we note an increasing of relative frequency, with a good linearity. In previous work we have shown that the variation of frequency versus temperature shows a very good linearity up to $1050{ }^{\circ} \mathrm{C}$ for AlN/Sapphire structure [12]. In this study, Iridium was used as the metal to fabricate IDT. However only one frequency (fundamental peak at $380 \mathrm{MHz}$ ) was considered due to the fact that no harmonic was generated. 


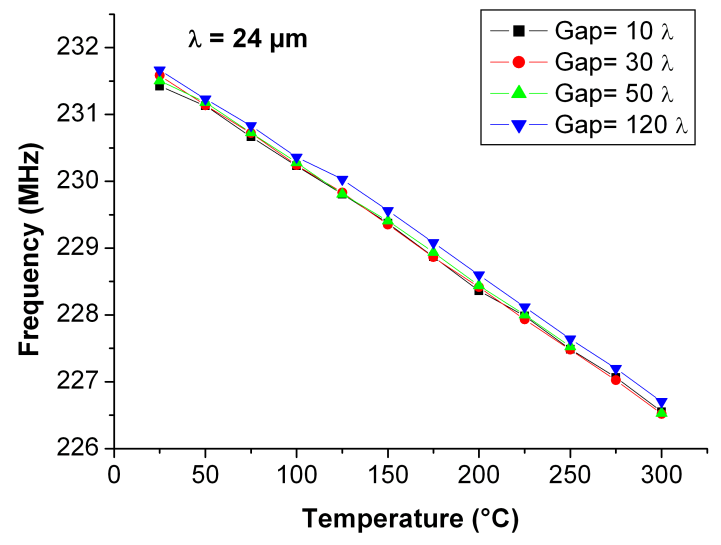

Fig. 8. Frequency variation versus temperature for various free-space delays.

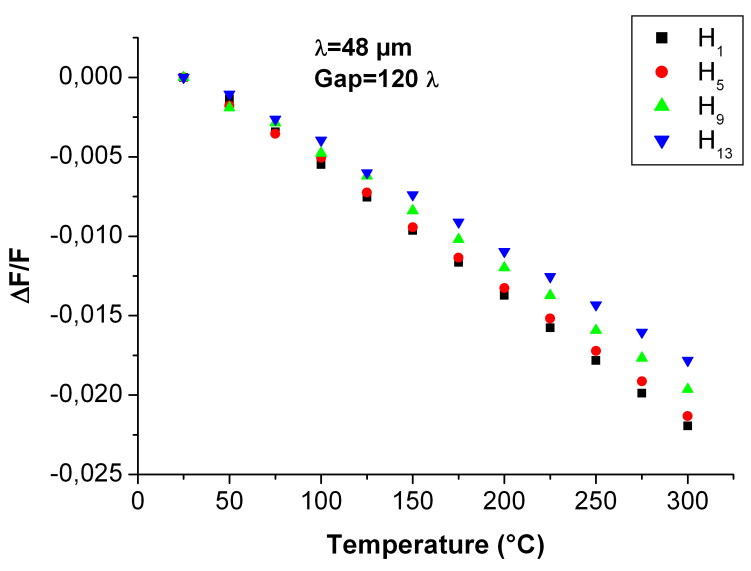

Fig. 9. Evolution of relative frequency variation versus temperature mesured for the device $(\lambda=48 \mu \mathrm{m}$, gap $=120 \lambda)$ and considering different harmonics.

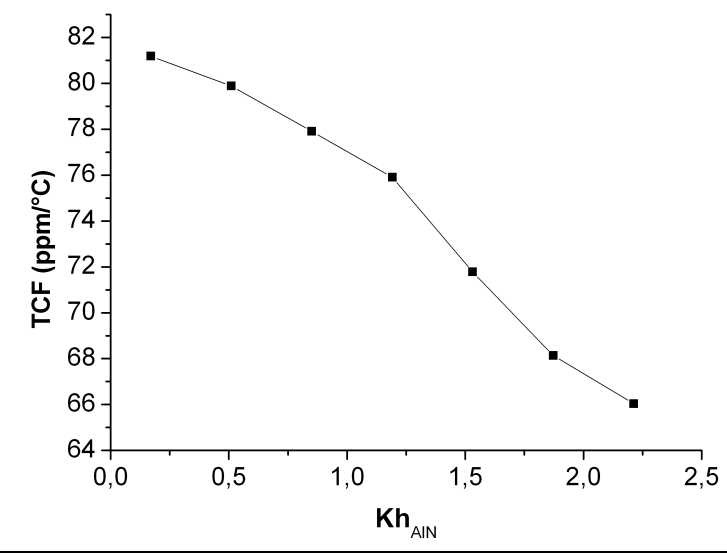

Fig. 10. Variation of the TCF of the AlN/Sapphire structure versus the normilized thickness of AlN film ( $\left.\mathrm{Kh}_{\mathrm{AIN}}\right)$ measured using several devices and and considering different harmonics.
The influence of TCF variation versus $\mathrm{Kh}_{\mathrm{AlN}}$, is shown in Figure 10. It seems clear that TCF value decrease with increasing of $\mathrm{Kh}_{\text {AIN }}\left(\mathrm{Kh}_{\mathrm{AIN}}=2 \pi \mathrm{h} / \lambda\right)$. According to the literature [13], it is possible to predict a value of TCF $=0$. This property allows us to manage the TCF value of the structure that is very important for sensor applications. Indeed, depending on the considered frequency band and the full range of the operating temperature, the SAW device can be designed to fully match the targeted application.

\section{CONCLUSION}

The authors present and discuss experiments that contribute to understanding the origin of insertion loss in the AlN/Sapphire structure and their evolution with temperature. Thus, variation of the electromechanical coupling coefficient was measured versus temperature using a SAW resonator and the insertion loss was measured using a SAW delay lines with various free-space delays.

Experimental results show that both $\mathrm{K}^{2}$ and $\alpha$ increase with temperature. While the increase of the latter was expected, the increase of the former is a pleasant surprise since it means that AlN/Sapphire structure could have a positive behavior with temperature. The variation of frequency with temperature shows a good linearity which is very useful for temperature sensor applications. Also, the TCF value is strongly dependent on the normalized thickness of AlN. This properties allows the design of SAW sensors with optimal TCF depending on target application. All our preliminary results attest that AlN/Sapphire structure is a promising solution as SAW substrate for high temperature application and shows a good alternative for LGS substrate when high frequency operation is required.

\section{REFERENCES}

[1] R. Fachberger, G. Bruckner, R. Hauser, C. Ruppel, J. Biniasch and L. Reindl, "Properties of radio frequency Rayleigh waves on langasite at elevated temperature," in Proc. IEEE Ultrason. Symp., 2004, pp. 12231226.

[2] M. Peireira da Cunha, R. J. Lad, T. Moonlight, G. Bernhardt and D. J. Frankel, "High temperature stability of langasite surface acoustic wave devices," in Proc. IEEE Ultrason. Symp., 2008, pp. 205-208.

[3] T. Aubert, O. Elmazria, B. Assouar, E. Blampain, A. Hamdan, D. Geneve, and S. Weber; "Investigations on AlN/Sapphire Piezoelectric Bilayer Structure for High-Temperature SAW Applications"; IEEE Trans. on Ultrasonics, Ferroelectrics and Frequency Control; Vol.59, pp 999-1005 (2012)

[4] T. Aubert, O. Elmazria, B. Assouar, L. Bouvot and M. Oudich, "Surface acoustic wave devices based on AlN/Sapphire structure for high temperature applications," Appl. Phys. Lett., vol. 96, pp. 203503, 2010.

[5] T. Aubert, M. B. Assouar, O. Legrani, O. Elmazria, C. Tiusan and S. Robert, "Highly textured growth of AlN films on sapphire by magnetron sputtering for high temperature surface acoustic wave applications," J. Vac. Sci. Technol. A, vol. 29, no. 2, pp. 021010, 2011.

[6] C. K. Campbell, "Obtaining the fundamental and harmonic radiation conductances of a reflective SAW interdigital Transducer" proc. 1998 IEEE Ultrasonics Symp., 1 (1998) 169-173.

[7] C. Caliendo, "Theoretical and experimental investigation of gigahertzband, temperature-compensated electromechanical coupling configurations based on AlN films," Appl. Phys. Lett., vol. 92, pp. 033505, 2008.

[8] O. Elmazria, M. El Hakiki, V. Mortet, M.B. Assouar, M. Nesladek, M. Vanecek, P. Bergonzo, and P. Alnot. "Effet of Diaond Nucleation 
Process on Propagation Losses of AIN/Diamond SAW Filter", IEEE Trans. on Ultras. Ferroel. Freq. Contr. Vol. 51, pp: 1704-1709, 2004.

[9] J. H. Hines and D. C. Malocha, "A simple equivalent circuit parameter extraction technique," in Proc. IEEE Ultrason. Symp., 1993, pp. 173177.

[10] F. Jungnickel and H.-J. Fröhlich, "Determination of transducer equivalent circuit and the coupling coefficient in SAW structures," Acoust. Ultrason., pp. 89-92, 1998.

[11] K. Hashimoto, Surface Acoustic Wave in telecommunication, Modeling and simulation, Springer-Verlag, Berlin, Heidlberg, New York, 2000

[12] Thierry Aubert, Omar Elmazria, Jochen Bardong, Gudrun, Badreddine Assouar; " Is AlN/Sapphire bilayer structure an alternative to Langasite for ultra-high-temperature SAW applications ?"; 2011 IEEE International Ultrasonics Symposium Proceedings, pp 2082-2085.

[13] K. Tsubouchi and N. Mikoshiba, "Zero-Temperature Coefficient SAW Devices on AIN Epitaxial Films"; IEEE Transactions on Sonics and Ultrasonics, Vol. SU-32, NO. 5, p 634-644 (1985) 